\title{
Contribuição do Design ao Programa de prevenção e assistência ao alcoolista (PARE) à comunidade de Londrina por meio de histórias em quadrinhos
}

\author{
Contribution of Design to the Prevention and Assistance Program Alchohol (Pare) of the \\ Community Through Londrina Comics
}

TOZATTI, Danielle de Marchi

Mestre, Universidade Estadual de Londrina

daniellemarchi@yahoo.com.br

\begin{abstract}
Resumo
Este trabalho contemplou o Design Gráfico, por meio de criação de Histórias em Quadrinhos produzidas pelos alunos do segundo ano do curso de Design Gráfico da Universidade Estadual de Londrina, contribuindo assim ao Programa de Prevenção e Assistência ao Alcoolista (PARE) à comunidade de Londrina. As atividades foram direcionadas a uma questão social relevante, atual e pertinente: a prevenção e tratamento do uso do álcool e drogas, por meio das Histórias em Quadrinhos aliada ao tratamento oferecido pelo PARE.
\end{abstract}

Palavras Chave: Design gráfico; Prevenção; História em quadrinhos.

\begin{abstract}
This work has included graphic design, by creating comic books produced by second year students of Graphic Design course at the State University of Londrina, thus contributing to the Program for Prevention and Assistance to alcohol (STOP) to the community in Londonderry. The activities were directed to a relevant social issue, current and relevant: the prevention and treatment of alcohol and drugs, through the comics along with the treatment offered by PARE.
\end{abstract}

Keywords: Design, Prevention, Comics.

\section{Introdução}

Pesquisar e escrever sobre temas tão distintos como Historia em Quadrinhos e Álcool não e tarefa fácil, mas de acordo com a experiência vivida por meio do Projeto de Extensão "Contribuição do Design ao Programa de prevenção e assistência ao alcoolista (PARE) à comunidade de Londrina por meio de histórias em quadrinhos", esta tarefa tornou-se interessante e gratificante.

O presente artigo procura abordar questões sociais, utilizando como ferramenta de design a Historia em Quadrinhos, identificando e estabelecendo dentro da instituição universitária parâmetros de abordagens.

Desde o primeiro momento o Design foi lembrado pelos componentes do projeto PARE como necessidade de abordagem e melhor utilização da comunicação aos usuários e pacientes de álcool da comunidade. 
Sendo assim este artigo tem por objetivo geral promover a construção de Historia em Quadrinhos que atendam as necessidades do projeto PARE, e como objetivos especificos trazer conhecimento e despertar a curiosidade dos estudantes do curso de design gráfico pelo tema abordado; promover discussões sobre o assunto e apresentar os resultados aos pacientes e usuários de álcool que freqüentam o projeto, alem de contribuir por meio do Design ao enriquecimento desta área de estudos.

A fundamentação teórica busca compreender a Historia em Quadrinhos brasileira, sua historia e contribuições sociais, a Arte seqüencial e o Humor. Questões relativas e latentes ligadas ao humor visual, entende-se "cultura de massa", esta forma de comunicação não verbal. Possibilitando assim o reconhecimento da mazela humana de forma irônica e satírica, por meio dos personagens e cenas construídas nas historias.

De acordo com Minayo (2000, p. 17) considera-se o ciclo da pesquisa como um processo de trabalho que dialeticamente termina num produto provisório e recomeça nas interrogações lançadas pela analise final. Partindo deste pressuposto a metodologia utilizada foi a busca do conhecimento por meio de palestras e discussões sobre álcool e drogas, aulas teóricas e praticas sobre historia em quadrinhos e entrevistas com o publico alvo de natureza exploratória.

Como resultado, espera a contribuição do design aos meios de comunicação, o humor consistiria no sentimento do contrario, provocado pela reflexão, que não se oculta nem se converte em forma de sentimento, mas em seu contrario, em sua negação, acompanhando o sentimento como uma sombra. Neste sentido o humor seria a reflexão que se exercita antes ou depois do fato cômico, conservando a possibilidade do contrario mas eliminando o nosso distanciamento e a nossa superioridade.

\section{A História em Quadrinhos Brasileira - Breve Relato}

Parte-se do pressuposto que as Histórias em Quadrinhos constituem uma instância possível de análise de formas não-verbais de comunicação, que vão por exemplo, da gestualidade à expressão cromática, passando do espaço social aos movimentos perceptíveis do corpo. Manifestação característica da chamada cultura de massa, as HQ's introduzem uma modalidade de comunicação (horizontal e coletiva) que poderíamos chamar de pluricódiga (segundo uma dimensão de convencionalidade) e multicanal (segundo uma dimensão de generalidade), cujo fim precípuo é o de permitir fácil percepção e pronto entendimento, como explica Trinta (1987).

A carga informativa (semântica e estética) das HQ's é imediatamente acessível, é portanto, de baixo custo informacional. $\mathrm{E}$ a isto deve ser somado um imperativo básico: clareza, antes de mais nada. As HQ's apresentam um discurso semioticamente rígido como, por exemplo, a evidência, a concorrência na sua textura de códigos analógicos (baseados na imagem) e digitais (com base na palavra impressa).

Para Cirne (1982, p.18) "os quadrinhos formam-se como um agenciamento/desencadeamento de imagens que se estruturam e se articulam a partir de cortes espaciais, temporais e gráficos acarretando um tempo narrativo capaz de problematizar o tempo da leitura". Sua especificidade, em sendo uma linguagem carregada de bens simbólicos e/ou elementos gráficos, implica uma história que tem início no século passado. 
Esta especificidade, já nasceria em função da história cultural. Ao contrário do cinema, que gerou seu próprio veículo, o quadrinho necessitou de um veículo alheio: o jornal. Das páginas semanais às tiras diárias e - muito tempo depois - às revistas exclusivas, o quadrinho construiu sua especificidade como indústria cultural.

Como prática significante, o quadrinho, assume a prática ideológica em sua concretude temático-gráfico-estrutural. Desse modo os quadrinhos seriam aparelhos ideológicos de estados culturais, esta discussão remete-se sem dúvida, para uma discussão política. A luta ideológica transforma-se em luta política contra a direita e os reformistas. A verdade é que a ideologia, nos quadrinhos, manifesta-se em todos os níveis, em quadrinhos supostamente inocentes, em quadrinhos de aventura tradicional, em quadrinhos liberais, em quadrinhos familiares, etc.

Discurso ideológico, o quadrinho é também discurso que se faz político (ao nível de sua especificidade). Assim como o ideológico manifesta-se mais níveis de articulação formal, o político manifesta-se em todos os níveis, seja de modo direto, seja de modo indireto, seja de modo crítico, seja de modo ideológico.

A luta pelo quadrinho brasileiro, em suas vertentes mais radicais, deve se inserir no interior da luta maior dos trabalhadores da cidade e do campo por uma perspectiva socialista para os destinos da nossa sociedade.

A proposta de um quadrinho político, de abertura socialista, sensibiliza ou sensibilizará o nosso quadrinheiro na medida em que ele participa de uma forma ou de outra, das aspirações das classes. Sensibilizará, de igual modo, os leitores.

Esta proposta atende à luta por um quadrinho novo, politicamente combativo, preventivo, que não se isola na luta geral por uma arte que também seja nova, e comprometida. Um quadrinho brasileiro politicamente combativo: a renovação gráfica e narrativa capaz de problematizar, atualizando os temas que se encontram na raiz de nossa cultura e de nossa tragédia política e social, a fome severina no nordeste; a antropologia dos mitos indígenas; a (sobre) vivência do operário nos grandes centros urbanos; o futebol, o carnaval e a macumba como expressões mágicas e ideológicas; as manifestações do folclore; o universo cantante da literatura de cordel; a história e a economia do país; o terror como possibilidade de um caminho temático a ser explorado politicamente. Um temário voltado para os nossos interesses, sempre em aberto, teria outros pontos expressivos, por exemplo, a repressão política, sexual e racista.

Ao nível gráfico, cumpre destacar a importância da relação cartum/quadrinhos para a prática quadrinizante brasileira e latino americana. Mas esta relação, que tem suas mediações narrativas e visuais não é exclusiva, nem esgota o que de melhor existe em nossa produção de quadrinho.

O cartum tem um discurso próprio segundo Eisner (1989), contudo, o quadrinho cartunístico é uma realidade semiológica. Como o quadrinho de terror é uma realidade editorial. Não pretendemos ser originais: são muitos os problemas (econômicos, gráficos, sociais, ideológicos, editoriais) que atingem os quadrinhos.

Mas se eles são colocados é porque temos condições concretas para resolvê-los, desde que não abandonemos a perspectiva socialista que orientará o projeto de uma sociedade em processo de transformação revolucionária. Como críticos preocupados com a produção cultural, com a possibilidade de quadrinho brasileiro, não nos fixamos no formal, antes faziamo-nos no problemático.

A tal qual a determina a sociedade burguesa, permanece, como conceito intangível em toda sua extensão. Não se atenta para o fato de que qualquer autor dramático 
tem algo de específico para exprimir ao seu tempo, e que ele não pode passar, sem comentário, de uma época a outra. O critério não está no formal, está no problemático (PISCATOR, 1968, p.43).

Feijó (1990) aponta para o caráter de cultura de massa da história em quadrinhos, organizada sobre bases industriais, cujo objetivo é atingir uma grande quantidade de leitores. Vários fatores contribuíram para o surgimento da história em quadrinhos no final do século XIX, entre eles a consolidação do capitalismo como forma de produção cultural, e causando o surgimento da indústria cultural. Isso somado à implantação da educação pública, criou uma nova classe de leitores na classe mais baixa da população.

No Brasil entre 1950 e 1960 as HQ’s com temática nacional começaram e se popularizar, o exemplo mais expressivo é a série Turma do Pererê, de Ziraldo, mas este fenômeno termina com o golpe militar em 1964, que vê essas manifestações como subversivas.

Sendo assim este artigo tem como objetivo apresentar as HQ's elaboradas a partir da temática do uso de álcool e outras drogas, proposta pelo Programa de Prevenção e Assistência ao Alcoolista (PARE), e direcionada na disciplina de História em Quadrinhos, aos alunos do segundo ano do curso de Design Gráfico da Universidade Estadual de Londrina.

\section{Arte Seqüencial}

De acordo com Capellari (2009, p. 51) "a arte seqüencial possui diversas formas de expressão. Está presente na pintura, no cinema, nos quadrinhos. É caracterizada pela disposição de duas ou mais imagens de forma a narrar uma história".

A principal diferença entre as modalidades de arte seqüencial mais populares na atualidade, que são o cinema, os quadrinhos e a animação, é que os quadrinhos simulam o movimento e a passagem do tempo através da seqüencia de imagens estáticas, enquanto o cinema e a animação criam a sensação de movimento real.

A definição mais aceita atualmente é dada por McCloud (1995, p. 9) "imagens pictóricas e outras justapostas em seqüencia delibarada destinadas a transmitir informações e/ou a produzir uma resposta no espectador".

A arte seqüencial, especialmente nas histórias em quadrinhos, é uma habilidade estudada, que pode ser aprendida, que se baseia no emprego imaginativo do conhecimento da ciência e da linguagem, assim como da habilidade de retratar ou caricaturar e de manejar as ferramentas do desenho. Na verdade, até um pedagogo se surpreenderia com a diversidade de disciplinas envolvidas na realização de uma história em quadrinhos média (EISNER, 1989, p. 144).

Não obstante a linguagem das HQ's não se dá pela simples interação entre imagem e texto. Apresenta particularidades que trazem consigo muitas questões que devem ser de conhecimento daquele que pretende produzir histórias em quadrinhos.

Ainda de acordo com Eisner (1989, p. 145) o estudo contínuo das técnicas de desenho é necessário:

Um domínio fundamental do desenho e da escrita é indispensável. Esta é uma forma de arte relacionada ao realismo, porque se propõe a contar histórias. A arte seqüencial lida como imagens reconhecíveis [...] um estudo sério de anatomia, perspectiva e composição, através de livros ou de cursos, constitui uma parte importante da formação [...]). A leitura regular, particularmente de contos, é 
essencial para a imaginação. Na prática, o artista “imagina” para o leitor. A leitura também constitui um importante banco de informações. Numa forma de arte em que o escritor/artista deve dominar um amplo repertório de fatos e informações sobre inúmeros temas, a aquisição de conhecimentos é interminável. Afinal, tratase de uma forma artística que trata da experiência humana.

Uma vez dito que história em quadrinhos são imagens pictóricas e outras justapostas em seqüencia deliberada destinadas a transmitir informações e/ou produzir uma resposta no espectador, McCloud (1995) evidencia que os quadrinhos se utilizam do sentido da visão para que aconteça a comunicação. Na mídia impressa, os quadrinhos são palpáveis, objetos a serem manuseados pelo leitor, porem seu conteúdo é percebido exclusivamente pela visão.

A partir dos anos 90, com o surgimento da internet como meio de comunicação disponível no âmbito doméstico, abriram-se novas possibilidades para a produção, bem como para a veiculação das HQ's.

A característica mais marcante da HQ é a fusão entre texto (linguagem verbal: palavra) e imagem (linguagem pictórica: imagem/desenho). Portanto, para compreender a dimensão artística dos quadrinhos é preciso analisar sua natureza híbrida, presente no texto, na imagem, na informação, no humor, etc.

Geralmente, as pessoas acham que o processo de escrever esta confinado à manipulação das palavras. O processo de escrever para uma narração gráfica esta relacionado com o desenvolvimento do conceito, a descrição dele e a construção da seqüência narrativa para traduzi-lo em imagens (EISNER, 2005, p. 115).

McCloud (1995, p. 67) afirma que os quadrinhos são um meio de comunicação baseado na conclusão do leitor, isto é, na sua participação voluntária, utilizando a imaginação para compreender um conjunto de imagens estáticas como uma seqüência contínua de acontecimentos. Por isso, o uso da imagens esta subordinado à experiência comum entre narrador e leitor.

O sucesso ou fracasso desse método de comunicação depende da facilidade com que o leitor reconhece o significado e o impacto emocional da imagem. Portanto, a competência da representação e a universalidade da forma escolhida são cruciais. O estilo e a adequação da técnica são acessórios da imagem e do que ela esta tentando dizer (EISNER, 1989, p. 13-14).

Estilo visual seria de fundamental importância segundo Eisner (2005, p. 159) "lembre-se de que este é um meio gráfico e o leitor absorve o tom e outras abstrações através da arte. $O$ estilo de arte não só conecta o leitor com o artista, mas também prepara a ambientação e tem valor de linguagem... Estilo, como nós o definimos aqui, é o "visual" e a "sensação da arte a serviço da sua mensagem".

\section{Humor}

"A vida se modificou, os costumes mudaram e os problemas são outros, mas a necessidade do ser de rir de suas próprias mazelas continua tão ou mais viva, dentro de cada um de nós, sendo possível acreditar que o humor é um elemento quase que vital para o equilíbrio da natureza humana" (MACHADO; GAUDENCIJ., 2003, p. 13).

Um dos principais motivos do humor é que nos faz pensar o que pode acontecer quando este resolve participar da retificação de nosso costumes e de nossas instituições e decide indicar, com o riso, que muita coisa em nós poderia ser melhor. 
Segundo Freud (Almanach, 1927, p.9-16), há duas maneiras pelas quais o processo humorístico pode realizar-se. A primeira é a ocorrência com uma pessoa isolada, que por si adota a atitude humorística, ao passo que uma segunda pessoa representa o papel de espectador; outra maneira é entre duas pessoas, uma das quais não toma parte alguma do processo humorístico, mas é tornada objeto de contemplação humorística pela outra.

Como os chistes e o cômico, o humor tem algo de liberador a seu respeito, mas possui também qualquer coisa de grandeza e elevação, que faltam às outras duas maneiras de obter prazer da atividade intelectual. Essa grandeza reside claramente no triunfo do afligido pelas provocações da realidade, a permitir que seja compelido sofrer. Freud insiste em que o afligido não pode ser afetado pelos traumas do mundo externo; demonstra, na verdade, que esses traumas para eles não passam de ocasiões para obter prazer.

\footnotetext{
O humor não é resignado, mas rebelde". É nessa rebeldia (ou teimosia, uma vez que a palavra alemã trotzig aceita também como tradução possível teimoso) que consiste a dimensão ética do humor, cujo sentido estacado por Freud é "não apenas o triunfo do ego, mas também o do princípio do prazer, que pode aqui afirmar-se contra a crueldade das circunstâncias reais. (KUPPERMANN, 2003, p.56).
}

A positividade da rebeldia própria do humor residiria justamente no fato de o humor poder ser considerado uma afirmação, pelo sujeito, da sua dimensão erótica e desejante, mesmo frente às adversidades que lhe são impostas pelo destino e pelo acaso. Pode-se concluir que a seriedade excessiva se afasta da rebeldia ética promovida pelo humor, na medida em que configura efetivamente uma anti-revolta que "passou então para o estado esmagado pela melancolia" (KUPPERMANN, 2003, p.57/8).

A rebeldia significa não apenas o triunfo do ego, mas também o do princípio do prazer, que pode aqui afirmar-se contra a crueldade das circunstâncias reais. Essas características - a rejeição das reivindicações da realidade e a efetivação do princípio do prazer - aproximam o humor dos processos regressivos ou reativos que tão amplamente atraem a atenção na psicopatologia. Seu desvio da possibilidade de sofrimento coloca-o dentro da extensa série de métodos que a mente humana construiu a fim de fugir à compulsão para sofrer - uma série que começa com a neurose e culmina com a loucura, incluindo a intoxicação, a auto-absorção e o êxtase.

Graças a essa vinculação, o humor possui uma dignidade que falta completamente, por exemplo, aos chistes, pois estes servem simplesmente para obter uma produção de prazer ou colocar sua produção, que foi obtida, a serviço da agressão.

A questão do humor torna-se extremamente importante neste caso, pois por meio dos HQ's produzidas pelos alunos e levadas ao pacientes atendidos pelo PARE, os mesmos de identificam com as situações riem, comentam, e principalmente se afligem ao refletir sobre a situação do personagem e compararem com sua vida vivida.

\section{Materiais e Métodos}

Procurou-se desenvolver este tema sobre a prevenção do uso do álcool em princípio e outras drogas para despertar a consciência dos próprios estudantes, sendo que este também seria o público alvo do programa PARE, e criar um elo entre o programa e as Histórias em Quadrinhos desenvolvidas pelos alunos, sendo que estes possuem base teórica e prática junto à disciplina de HQ no curso de Design Gráfico, podendo levar a informação, 
neste caso da prevenção de forma inusitada, utilizando assim o conteúdo circular e somando à pratica do programa PARE.

Segundo informações obtidas nos manuscritos do PARE (2004), a UEL, preocupada com questões relacionadas ao uso e abuso de substâncias psicoativas, instituiu, em 1984, o PARE - Programa de Prevenção e Assistência ao Alcoolista - Reintegração e Educação, que atua na prevenção e no tratamento de servidores, docentes e estudantes com problemas relacionados ao abuso ou dependência de álcool.

Considerando a relevância deste programa, assim como uma vertente que tem sido explorada pela atividade do design - mais propriamente o design social - e diante das discussões em torno da responsabilidade social que deve ser exercitada, resolveu-se atender ao convite, comovidos pela situação, a fim de contribuir com a comunicação de aspectos de prevenção desta doença, mal que atinge grande parte da população brasileira.

Os alunos envolvidos participaram de palestras com a psicóloga do PARE, obtendo informações a cerca do programa e do uso de álcool, para depois criarem o roteiro, personagens, cenas, narrativas, e outros elementos gráficos necessários à construção adequada da $\mathrm{HQ}$.

Segue algumas imagens produzidas na revista de HQ sobre o PARE, das alunas Maira Zorzeto e da aluna Lívia Lopes Sant’anna em 2006 selecionadas para este trabalho. A aluna Maira Zorzeto faz referências a pessoas para indicar as determinadas situações, com imagens próximas ao realismo,como no primeiro caso a personagem Rosicléia, que apresenta o soluço ao falar o nome RosıCléia, esta faz referência aos usuários habituais do álcool, que quase todos os dia saem para beber, e acabam perdendo o respeito próprio e a identidade.

No segundo caso temos o personagem MaurlCio, que representa o usuário recreacional de álcool, que bebe com os amigos, arruma confusão e geralmente é jovem.

No terceiro caso conhecemos o EurlCo, um homem que é identificado como usuário abusivo do álcool, ele bebe todos os dias, e devido à dependência perdeu a família e o emprego.

Para finalizar pergunta-se: Você se identificou com algum dos personagens? Veja o que ainda pode acontecer com um alcoolista. E segue a figura humana indicando todos os problemas possíveis aos usuários de álcool. Na contra-capa temos informações sobre o PARE, caso a resposta a pergunta anterior foi sim. Segue a HQ criada pela aluna Maira Zorzeto em 2006. 

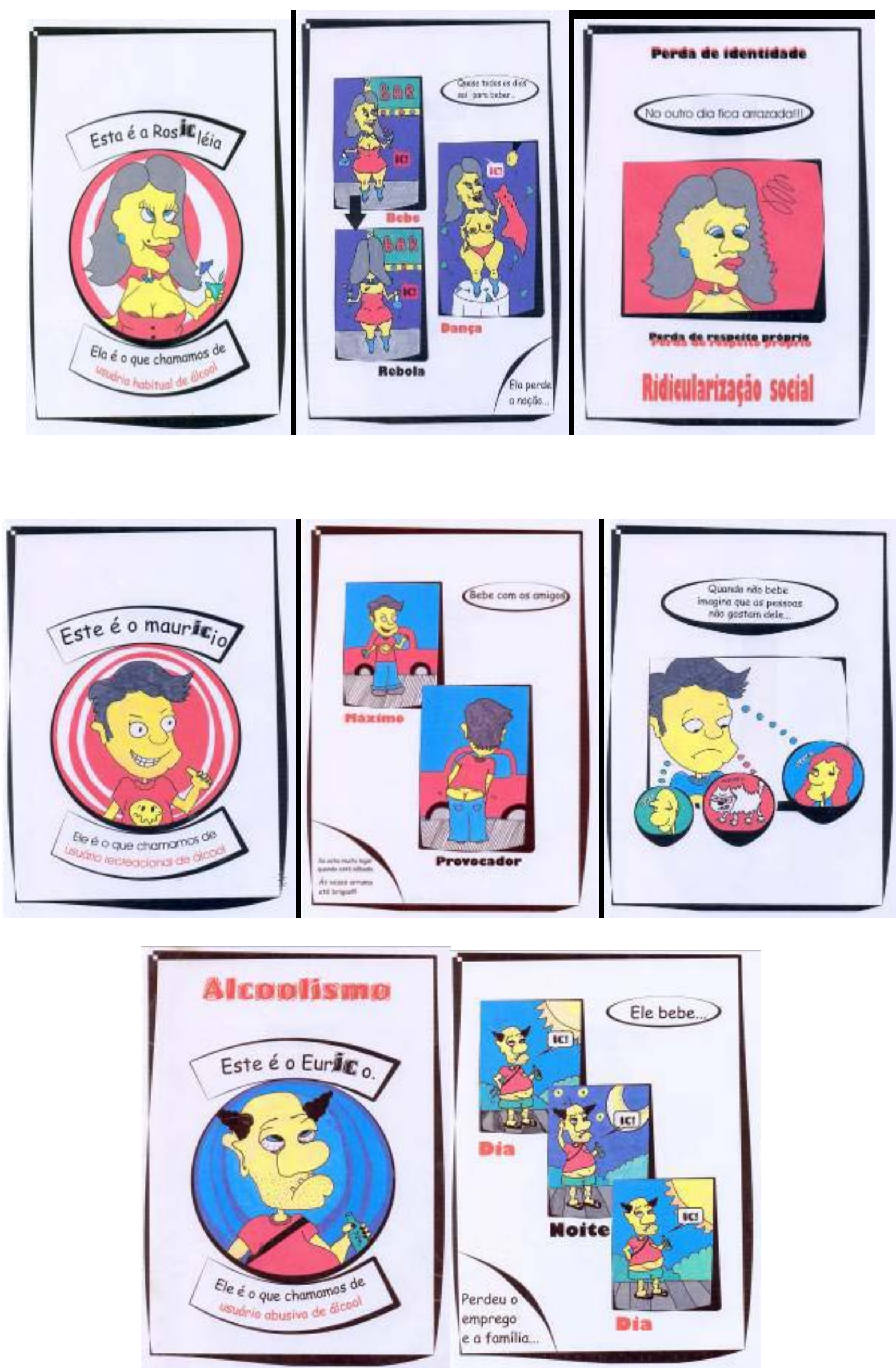


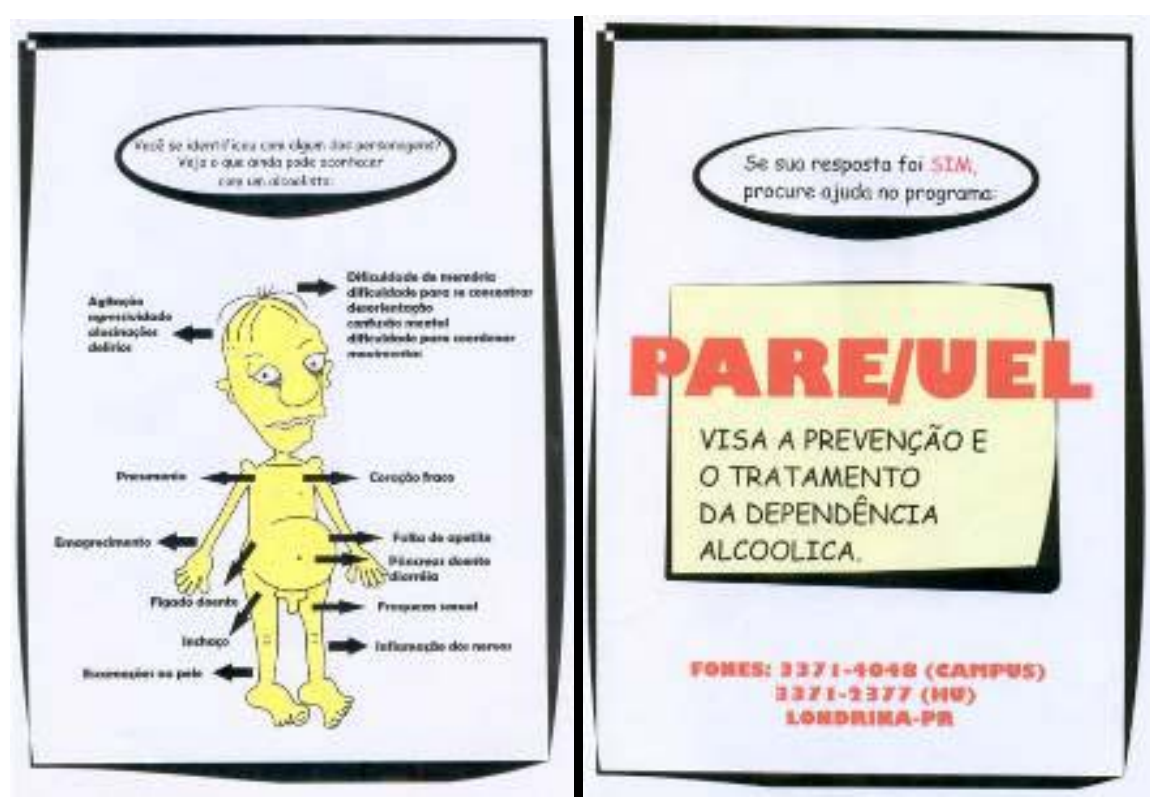

Já a aluna Lívia Lopes Sant Anna, optou por apresentar a temática da família que sofre com o alcoólatra, esta família é composta pelo pai "Jinho", pela mãe "Genice", pela filha "Lia". O pai sai para trabalhar, volta bêbado, a filha se preocupa com ele, não apresenta rendimento na escola, e acaba preocupando a professora Rose, e a mãe se compromete a ajudar o pai a buscar recurso no PARE, enfatizando a problemática social familiar, quando os pais fazem uso do álcool ou outras drogas e acabam repercutindo nos filhos, em suas vidas escolares, psicológicas, sociais, etc.

Esta aluna usa traços infantis e cores que determinam medo. Segue alguns quadrinhos selecionados para exemplificar a $\mathrm{HQ}$ criada pela aluna.

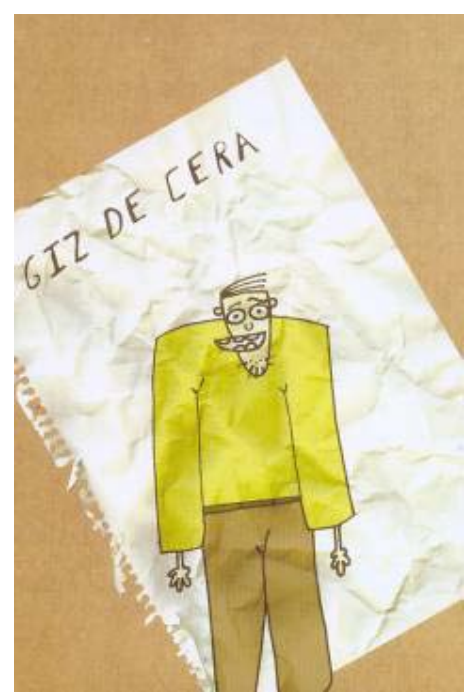

Capa da HQ intitulada Giz de Cera, com a imagem do pai "Jinho". 


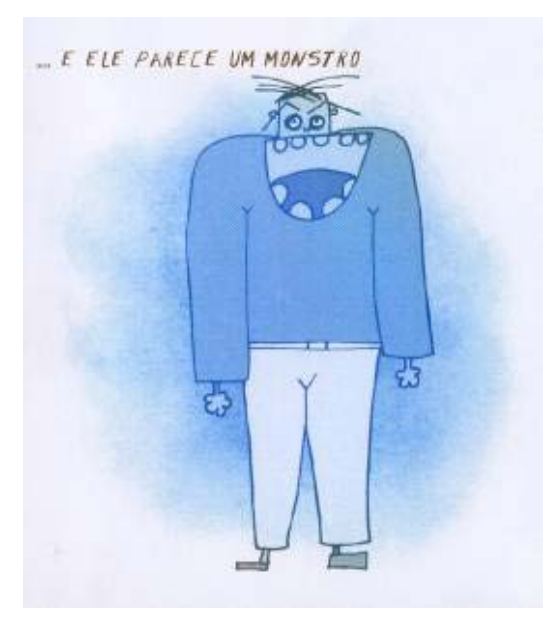

A filha pensa no pai como um monstro

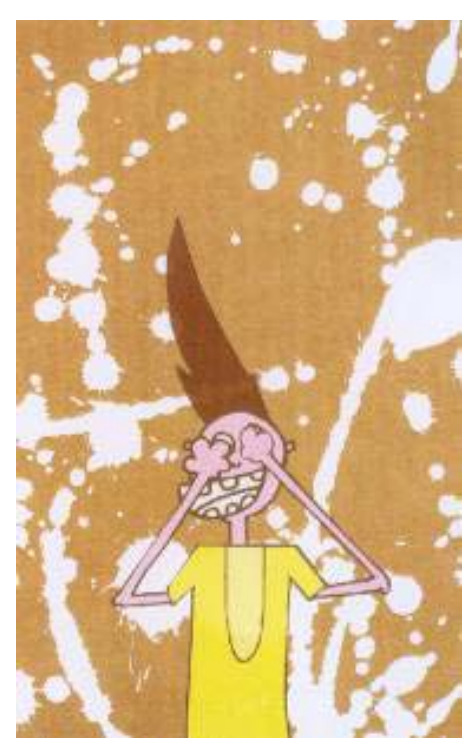

A filha "Lia" preocupada e com medo do pai tampa os olhos.

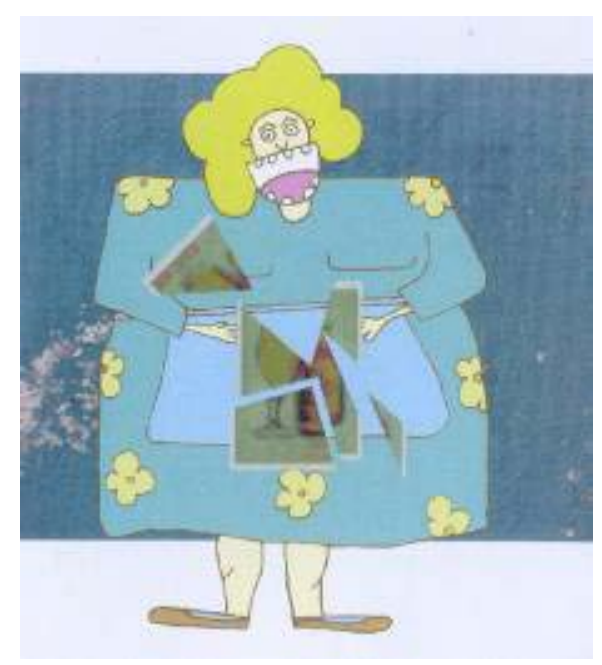


A mãe "Genice" promete a filha que tudo isso vai acabar e que a ama muito, enquanto rasga o cartaz de cerveja.

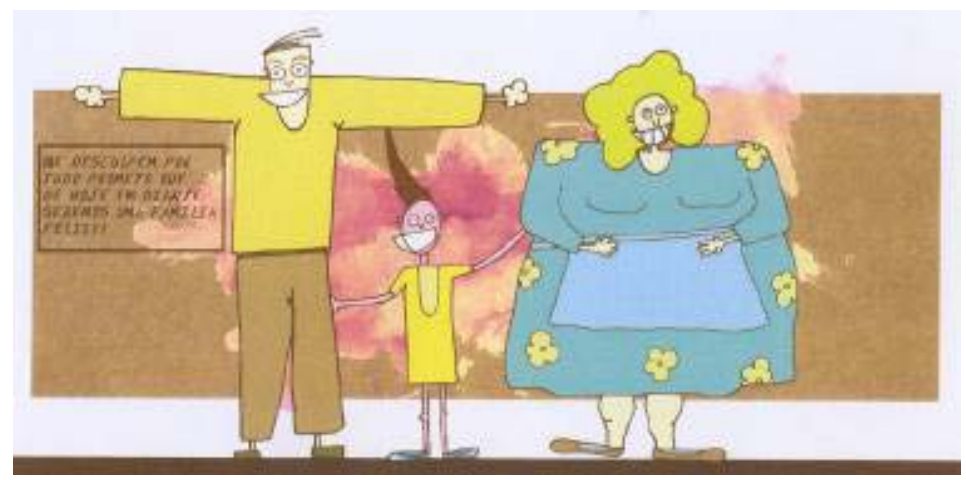

Imagem da família, o pai "Jinho"se redime pedindo desculpas "me desculpem pó tudo prometo que de hoje em diante seremos uma família feliz".

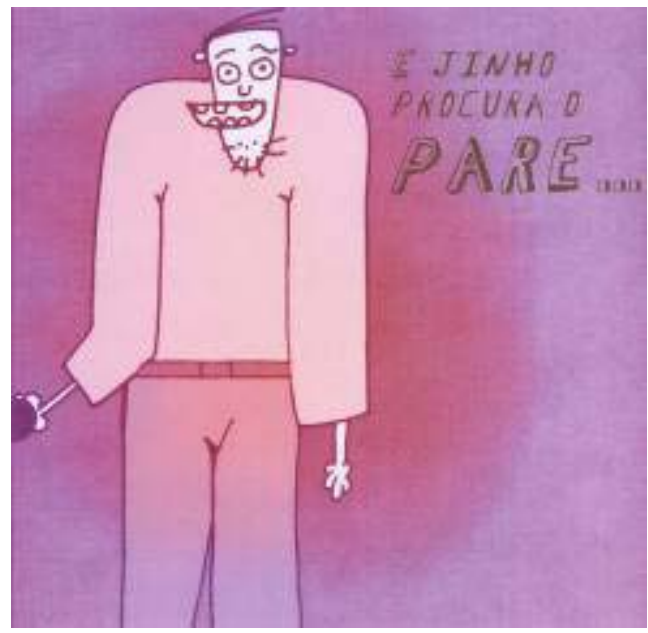

Jinho finalmente procura ajuda no PARE, depois que a professora de Lia escreve um bilhete dizendo que eles precisam cuidar e pensar na filha.

\section{Considerações Finais}

Diversas Histórias foram criadas pelos alunos do segundo ano do curso de Design Gráfico (UEL), que obtiveram informações relevantes sobre o uso do álcool, por meio de palestras com psicólogo e assistente social, leitura de materiais relacionados ao assunto, discussão e abordagem do tema para posteriormente iniciarem a criação do roteiro, desenvolvimento dos personagens, diagramação e finalização da História em Quadrinhos. Estes trabalhos resultaram em abordagens aos pacientes do PARE, exposições na Universidade Estadual de Londrina, tema de Trabalho de Conclusão de Curso, entrevista, além de uso das História em Quadrinhos em algumas disciplinas o Decreto Estadual n. 4.588/05. Tal decreto solicita a inclusão nas disciplinas afins, que informe e esclareça sobre Cidadania, Qualidade de Vida, no enfoque de prevenção ao uso inadequado de drogas licitas e ilícitas.

Desta forma as Histórias em Quadrinhos foram programadas de forma sistematizada, bilateral (conhecimento acadêmico e sociedade) e direcionada a uma questão 
social relevante, atual e pertinente: a prevenção e tratamento do uso do álcool e drogas pela comunidade em geral.

Tradicionalmente associados ao humor e ao entretenimento, as histórias em quadrinhos podem parecer uma opção pouco convencional para discutir temas delicados, políticos e sociais, entre outros. O jornalista Joe Sacco, em entrevista ao Jornal Folha de São Paulo (Caderno Mundo, A15, 19/04/2001) acredita que a linguagem da HQ seja capaz de superar o bloqueio do grande público com temas pouco palatáveis. "Os quadrinhos tem muito apelo em razão das imagens. Assim, conquista-se a atenção do leitor, é capaz de contar a ele histórias difíceis e introduzir a informação" (Ibid).

O leitor cotidiano, colocado num plano de vivência imediata com a mensagem gráfica, recebe o mosaico de significações como um jato de água fria. Está longe de apreender-lhe os paradoxos, longe mesmo de aprendê-la com totalidade. Mas a imagem vai acompanhá-lo pelo dia adentro, num trabalho paciente de sedimentação das significações digeridas e dirigidas.

Espera-se que com este trabalho mais especificamente de História em Quadrinhos, tenha novos valores no Design. Este tipo de humor gráfico imita as deformidades, os erros da sociedade, através de personagens representativos do cotidiano social, assim o leitor, levado pela ironia e pelo humor é afligido pelas provocações da História em Quadrinhos e consegue obter prazer, levado por um humor rebelde, que o faz rir das circunstâncias reais, e pensar na situação atual da sua vida.

Decorrente da imagem humorística a crítica imposta nas HQ's leva-nos ao debate sobre o sentido do humor, a idéia de mercado e de valor utilitário cada vez mais presente. Para que serve o humor? Ele é útil ou inútil? É instrumento de crítica social ou mera diversão? Até que ponto a idéia de valor utilitário é incompatível com a idéia de diversão? Velloso (1996, p.61) a afirma que "[...] o humor é polissêmico: ele é capaz de incluir a idéia de combate, passatempo, denúncia, diversão, irreverência e informação".

Dentro deste universo este artigo espera ter contribuído com as HQ's geradas pelos alunos e apresentadas aos pacientes do projeto PARE, que ao se depararem com os personagens criados, riem, se reconhecem, e se conscientizam com a informação.

\section{Referências}

CAPELLARI, Marcia S. V. Histórias em quadrinhos e cinema: meios cada vez mais próximos no ambiente digital. Disponível em:

$<$ http://revistaseletronicas.pucrs.br/famecos/ojs/index.php/famecos/article/view/5910>. Acesso em $10 \mathrm{dez} .2010$.

CIRNE, Moacy. Uma introdução política aos quadrinhos. Rio de Janeiro: Achiamé, 1982.

EISNER, Will. Quadrinhos e arte sequencial. São Paulo: Martins Fontes, 1989.

FEIJÓ, Mário. Quadrinhos em ação. São Paulo: Moderna, 1997.

FREIRE, Rosane. O. D. Historia em quadrinhos: arte ou industria cultural? 2010. Trabalho de Conclusão de Curso (Graduação em XXXXXX) ) - Universidade Estadual de Londrina, 2010 
FREUD, Sigmund. Obras psicológias completas: os chistes e sua relação com o inconsciente. Rio de Janeiro: Imago, 1975.

FREUD, Sigmund. Revista Almanach, 1927, p.9-16.

KUPPERMANN, Daniel. Ousar rir: humor, criação e psicanálise. Rio de Janeiro: Civilização Brasileira, 2003.

MACHADO, José; GAUDENCI J. Heitor. Piracicaba 30 anos de humor. São Paulo: Imprensa Oficial do Estado, 2003.

McCLOUD, Scott. Desvendando os quadrinhos. São Paulo: Makron Books, 1995.

MINAYO, Maria Cecília de Souza. O desafio do conhecimento: pesquisa qualitativa em saúde. Rio de Janeiro: Abrasco, 2000.

PISCATOR, Erwin. Teatro político. Rio de Janeiro: Civilização Brasileira, 1968.

PROGRAMA DE PREVENÇÃO E ASSISTÊNCIA AO ALCOOLISTA (PARE). Uso e abuso de substâncias psicoativas. Londrina: UEL, 2004.

TRINTA, Ramos Aluízio. História em quadrinhos e comunicação não-verbal. São Paulo, 1987.

VELLOSO, Mônica Pimenta. Modernismo no Rio de Janeiro: turunas e quixotes. Rio de Janeiro: Fundação Getúlio Vargas, 1996. 